\title{
POPs' effect on cardiometabolic and inflammatory profile in a sample of women with obesity and hypertension
}

\author{
Ana Ferro, Diana Teixeira, Diogo Pestana, Rosário Monteiro, Cristina C.Santos, Valentina F. \\ Domingues, Jorge Polónia \& Conceição Calhau
}

\begin{abstract}
Persistent organic pollutants (POPs) are man-made compounds with metabolic disruption impact. We investigated the effect of POP exposure in the cardiometabolic and inflammatory profile in a population of women with obesity and hypertension. In 43 premenopausal women ( 22 treated vs. 21 nontreated) undergoing bariatric surgery, blood and adipose tissue samples (visceral (vAT) and abdominal subcutaneous (scAT)) were collected. Median concentrations of $\sum \mathrm{HCH}$ and $\sum$ POPs in vAT were significantly higher in treated women. VAT $\sum \mathrm{HCH}$ and scAT $\sum \mathrm{HCH}$ and $\sum$ POPs concentrations were positively correlated with systolic blood pressure in the non-treated group. Our findings suggest that exposure to POPs and its accumulation in vAT and circulating in plasma may be associated to a higher cardiovascular risk in women with obesity and hypertension, with or without antihypertensive treatment.
\end{abstract}

Keywords: Cardiometabolic risk, hypertension, inflammation, obesity, persistent organic pollutants

\section{Introduction}

Incidence and prevalence of obesity is increasing worldwide and it is associated with several disorders, such as diabetes, hypertension, cardiovascular and liver disease and neoplastic disease. $\frac{1-3}{}$ Despite its multifactorial etiology, it has been suggested the influence of certain environmental agents described as persistent organic pollutants (POPs) that have endocrine disruption effects. $\frac{4-6}{}$ These POPs are man-made compounds derived primarily from industrial activities. POPs' combinations contaminate the air, soil and water; however, humans' exposition occurs primarily through dietary sources, especially fatty foods of animal origins, such as milk, meat and fish. ${ }^{7}$ These synthetic chemicals are or were used as pesticides, plasticizers, antimicrobials, among others. $\underline{8}$

The association of obesity and high blood pressure increases the probability of numerous cardiovascular events. Hypertension has many known risk factors, for instance genetic influence, age, race, gender, smoking, stress, renal abnormalities and endocrine function, diet, and exercise..$^{9}$ This condition is a major risk factor for stroke, coronary events and heart and renal failure. $\frac{10}{}$ Nevertheless, there are some studies that suggest that exposure to POPs may be an additional factor to hypertension development in a younger age and a greater severity of this condition..,$\underline{11}$ 
POPs are lipophilic substances environmentally and biologically persistent, which leads to their bioaccumulation predominantly in the adipose tissue (AT),,$\underline{5,12}$ Despite the protective profile of this preferential bioaccumulation, it soon becomes deleterious, because AT turns into a continual source of internal exposure to POPs, besides its role in metabolism. For instance, they are called environmental "obesogens" because they inappropriately regulate and promote lipid accumulation and adipogenesis. $\underline{6}$

Even though the relationship of POPs and its influence with cardiovascular disease and metabolic syndrome has been studied by different groups, there haven't been many studies toward hypertension. $\underline{5,11,13-19}$ Indeed, although recent studies have observed an association between exposition to POPs and higher prevalence of hypertension, with putative disruption of normal blood pressure levels and increased odds of hypertension. $\underline{20,21}$ Further observational studies are still needed to better understand this potential effect. Putative biological mechanisms could involve vascular dysfunction and cardiac hypertrophy. $\underline{22-24}$

Thus, it will be relevant to investigate the effect of POP exposure in the cardiometabolic and inflammatory profile in a population of women with obesity and hypertension, and whether the presence, or absence, of an antihypertensive therapy influence the observed effects.

\section{Materials and methods}

\section{Study participants}

This study was conducted in 43 premenopausal women with obesity and hypertension (22 treated with antihypertensive drugs and 21 non-treated for this condition) with an age range of 22-59 years old undergoing bariatric surgery at the General Surgery Department, S. João Hospital (Porto, Portugal). These patients met the criteria for bariatric surgery according to the country's Department of Health latest criteria: BMI (body mass index) $\geq 40 \mathrm{~kg} \mathrm{~m}^{-2}$ or BMI $\geq 35 \mathrm{~kg} \mathrm{~m}^{-2}$ with at least one comorbidity, such as hypertension, dyslipidemia, type 2 diabetes, or obstructive sleep apnea syndrome. These patients had diagnosed hypertension and the information about the treatment or absence of treatment is according to data collected from their clinical information. Over this article we sorted the sample into two different clusters named "treated women" (women with obesity and hypertension under antihypertensive therapy) and "nontreated women" (women with obesity and hypertension without antihypertensive therapy prescribed). In means of comparison, it was also analyzed a sample of 19 women with obesity, but without hypertension that met the criteria mentioned above. In this secondary analysis, it was performed a comparison between the group of women without hypertension and the group of nontreated women and between the group of women without hypertension and the group of treated women. All participants were recruited between January 2010 and June 2011 and signed informed consent to participate in the study. This investigation was conducted according to the Declaration of Helsinki and approved by the Hospital's Ethics Committee. Socio-demographic characteristics, anthropometric characteristics, clinical history, life-style factors, parity and occupation were collected from the Medical Support System of S. João Hospital (Porto, Portugal).

\section{Clinical and biochemical parameters}


At baseline were measured anthropometric parameters, adiposity-related markers and various clinical variables. BMI $\left(\mathrm{kg} \mathrm{m}^{-2}\right)$ was calculated from the measured weight and height both pre-operatively. Blood samples were collected after an overnight fast and analyzed by the Department of Clinical Pathology of the S. João Hospital (Porto, Portugal). Then measures of insulin resistance (HOMA-IR) and pancreatic beta cell function (HOMA-B) were assessed with the homeostatic model assessment (HOMA2). $\underline{25}$

Routine serum chemistries were measured using conventional methods with an Olympus AU5400 ${ }^{\circledR}$ automated clinical chemistry analyzer (Beckman-Coulter ${ }^{\circledR}$, Izasa, Porto, Portugal). The biological parameters evaluated included fasting blood glucose and insulin, lipid profile [total cholesterol, high-density lipoprotein (HDL) cholesterol, lowdensity lipoprotein (LDL) cholesterol and triglycerides] and high-sensitivity C-reactive protein (hsCRP). Low-density lipoprotein (LDL) cholesterol was calculated according to Friedewald's equation. $\underline{26}$ Finally, we used the Framingham risk score to estimate the 10 year CVD risk (person's chance of developing cardiovascular disease in the next 10 years) of these individuals. .77

All variables presented below refer to measurements made at baseline.

\section{Adipose tissue management}

Human AT samples were collected from visceral (vAT) and abdominal subcutaneous (scAT) tissue during bariatric surgery. These samples were coded, processed and stored at $-80{ }^{\circ} \mathrm{C}$.

Adipocyte size was measured as previously described by Pestana et al. $\underline{5}$ The procedure included fixation in buffered formaldehyde $10 \%$ for at least $48 \mathrm{~h}$ at $4{ }^{\circ} \mathrm{C}$, dehydration and finally embedded in fresh paraffin. Using a Leica ${ }^{\circledR}$ Microtome (RM2125RT, Lisbon, Portugal), it was obtained 3- $\mu \mathrm{m}$-thick sections that were stained with hematoxylin-eosin to assess morphology. Digital images were acquired with a fluorescence microscope (Nikon Eclipse $50 \mathrm{i}^{\circledR}$, Melville, USA), at a magnification of $200 \times$ from five randomlyselected fields. Then the area of the adipocytes, $\sim 90$ adipocytes for vAT and 60 adipocytes for scAT, was measured with ImageJ software ${ }^{\circledR}$ (National Institute of Health, Bethesda, USA).

\section{Assessment of POPs concentrations in plasma and adipose tissue}

It was studied the presence of thirteen different POPs such as aldrin, dieldrin and endrin [bought from Pestanal Fluka ${ }^{\circledR}$ (Madrid, Spain)], hexachlorobenzene (HCB) and hexachlorocyclohexane lindane (HCH Lindane) [bought from Pestanal Riedel-de Haën ${ }^{\circledR}$ (Madrid,Spain)], $\Sigma$ hexachlorocyclohexane $(\Sigma \mathrm{HCH})$ (sum of $\alpha-\mathrm{HCH}, \beta-\mathrm{HCH}$ and $\delta$ $\mathrm{HCH}$ ) [obtained from Sigma-Aldrich ${ }^{\circledR}$ (Madrid,Spain)]. EndosulfanI, endosulfanII, methoxyclor, 2, 3, 7, 8-tetrachlorodibenzodioxin (TCDD), $p$, $p^{\prime}$-dichlorodiphenyldichloroethane ( $p, p^{\prime}$-DDD) and $p, p^{\prime}$-dichlorodiphenyltrichloroethane $\left(o, p^{\prime}\right.$-DDT) [purchased from Supelco ${ }^{\circledR}$ (Madrid,Spain)]. $p, p^{\prime}$-dichlorodiphenyldichloroethylene ( $p, p^{\prime}$-DDE) [obtained from ChemService ${ }^{\circledR}$ (WestChester, United States of America (USA)].

The POPs aforementioned were quantified in plasma samples stored at $-80{ }^{\circ} \mathrm{C}$ collected preoperatively. The samples were analyzed using the methodology described by Covaci ${ }^{28}$ with adjustments described by Teixeira ${ }^{16}$ namely the involvement of solid-phase 
extraction and final determination using a gas chromatograph coupled to an electron capture detector (GC-ECD). Results were expressed as nanograms per milliliter of plasma and represent a mean of three individual injections of the same sample.

In turn, POPs' analysis in AT was performed according to the method described by Fernandes et al. ${ }^{29}$ The procedure included standardized extraction of $200 \mathrm{mg}$ of AT, clean up using solid phase extraction columns Strata C18-E (SPE, $500 \mathrm{mg} / 3 \mathrm{~mL}, 55 \mathrm{~mm}$ ), purchased from Phenomenex (Torrance, CA) and quantification by gas chromatography with electron-capture detection (GC-ECD) a Shimadzu GC-2010, equipped with a capillary column of $30 \mathrm{~m}$ ZB-XLB $(0.25 \mathrm{~mm}$ i.d. $0.25 \mu \mathrm{m}$ film thickness, ZebronPhenomenex). 4-4'-dichlorobenzophenone was used as internal standard. The results were expressed as ng of POPs/g of fat and are a mean of three individual determinations of the same sample.

The methods were validated by measuring linearity and limits of detection (LOD) and quantification (LOQ) ${ }^{\underline{29}}$ according to $\mathrm{ICH}$ guidelines (ICH,2005). For analysis purposes, only the POPs measured above LOD were considered (positive samples). Agreement in the retention time in the sample and in the reference standard was also required to confirm a positive result.

\section{Cytokines measurement}

Interleukin (IL) 6, IL-10, monocyte chemotatic protein-1 (MCP-1) concentrations in plasma were measured using, respectively, LEGEND MAXTM Human IL-6, IL-10, MCP-1 ELISA kits (BioLegend, San Diego, CA), according to the manufacturer's instructions.

\section{Statistical analyses}

Statistical analyses were performed using Statistical Package for Social Sciences (SPSS, 22.0 version statistical software, IBM Corp ${ }^{\circledR}$, New York, USA). Because of the skewed distribution of data, variables are summarized with frequencies, median (minimum, maximum). Mann-Whitney test was used to compare the clinical and biological characteristics and the concentration of the different POPs in the different depots between treated and non-treated women for hypertensive disease. To compare women with or without hypertension, either with or without treatment, Mann-Whitney test with Bonferroni correction for multiple comparisons was used.

The association between POPs concentration in vAT, scAT and plasma and the various clinical parameters was estimated by Spearman correlation coefficients. All tests were two-tailed and $p<0.05$ were regarded as significant.

Although the sum of POPs was calculated by the sum of the thirteen pollutants abovementioned, it was only possible to assess correlations with the sum of $\mathrm{HCH}, p, p^{\prime}$-DDE and the sum of POPs, since the others isolated compounds investigated had low detection frequencies.

\section{Results}




\section{Clinical and biological markers}

The comparison of the clinical and biological parameters between treated and non-treated women is shown in Table 1. Because our cohort is a group of premenopausal obese women, it was not expected to be any significant difference related to age. Regarding the anthropometrics, there was no statistically significant difference between the two groups in BMI, waist/hip ratio or vAT adipocyte area, however scAT adipocyte area was significantly higher in nontreated women (median $=5323.3 \mathrm{vs}$ median $=6271.8 \mu \mathrm{m}^{2}$, $p=0.048$ ). Neither the lipid profile nor glucose homeostasis or hepatic function presented any significant difference between the two clusters. Regarding blood pressure, there was no significant difference between treated or non-treated women with hypertension. In addition, it was found no significant difference in IL-6, IL-10, MCP-1, and C-reactive protein between the two clusters. The comparison of 10-year cardiovascular disease (CVD) risk revealed no statistically significant difference.

\section{Table 1. Clinical and biological characteristics of the patients.}

\begin{tabular}{|c|c|c|c|c|c|}
\hline \multirow[b]{2}{*}{ Parameters } & \multicolumn{2}{|r|}{ Treated women } & \multicolumn{2}{|r|}{ Nontreated women } & \multirow[b]{2}{*}{$\rho$ value } \\
\hline & $N$ & Median (minimum, maximum) & $n$ & Median (minimum, maximum) & \\
\hline Age (years) & 22 & $40.5(22.0,59.0)$ & 21 & $36.0(22.0,54.0)$ & 0.645 \\
\hline Obesity evolution (years) & 22 & $19.0(8.0,33.0)$ & 21 & $19.0(5.0,32.0)$ & 0.632 \\
\hline BMI $\left(\mathrm{kg} \mathrm{m}^{-3}\right)$ & 22 & \begin{tabular}{|l|l}
$45.6(36.8,56.2)$ \\
\end{tabular} & 21 & $44.1(37.5,53.5)$ & 0.645 \\
\hline Waist//ip ratio & 15 & $0.92(0.76,1.04)$ & 20 & $0.59(0.75,1.06)$ & 0.854 \\
\hline \multicolumn{6}{|l|}{ Plasma lipid profile } \\
\hline Total cholesterol $\left(\mathrm{mg} \mathrm{dL}^{-1}\right)$ & 22 & $207.5(157.0,287.0)$ & 21 & $169.0(114.0,300.0)$ & 0.093 \\
\hline Total triglycerides $\left(\mathrm{mg} \mathrm{dL}^{-1}\right.$ ) & 22 & $\mid 129.5(66.0,261.0)$ & 21 & $96.0(53.0,229.0)$ & 0.165 \\
\hline HDL eholesterol ( $m g$ al $L^{-1}$ ) & 22 & $44.5(34.0,81.0)$ & 21 & $52.0(31.0,74.0)$ & 0.171 \\
\hline LDL cholesterol $\left(\mathrm{mg}_{\mathrm{al}} \mathrm{LL}^{-1}\right)$ & 22 & $135.5(100.0,162.0)$ & 21 & $119.0(58.0,206.0)$ & 0.438 \\
\hline \multicolumn{5}{|c|}{ Glucose homeostasis } & \\
\hline HOMA2-B (96) & 22 & $142.9(31.9,229.5)$ & 19 & $139.6(13.1,263.7)$ & 0.885 \\
\hline \multicolumn{6}{|l|}{ Blood pressure } \\
\hline Systolie blood pressure $(\mathrm{mm} \mathrm{H} \mathrm{H})$ & 18 & $130.0(110.0,170.0)$ & 21 & $147.0(120.0,171.0)$ & 0.145 \\
\hline Disstolic blood pressure $(\mathrm{mm} \mathrm{Hg})$ & 18 & $80.0(66.0,108.0)$ & 21 & $90.0(70.0,120.0)$ & 0.863 \\
\hline \multicolumn{6}{|l|}{ Inflammatory parameters } \\
\hline IL6 (pg mL-12) & 18 & $27.9(4.3,99.1)$ & 16 & $28.5(7.0,129.5)$ & 0.731 \\
\hline FL10 $\left(p g \mathrm{~mL}^{-1}\right)$ & 21 & $4.4(0.3,104.0)$ & 18 & $5.2(1.3,69.9)$ & 0.863 \\
\hline IL6/L1L10 & 18 & $10.5(0.7,90.3)$ & 16 & $7.8(0.4,213.1)$ & 0.731 \\
\hline MCP1 $\left(p g \mathrm{~mL}^{-1}\right)$ & 21 & $103.8(17.0,202.7)$ & 19 & $\mid 117.3(27.9,272.7)$ & 0.527 \\
\hline \multicolumn{6}{|l|}{ Other parameters } \\
\hline hsc-resctive protein (mg $\left.\mathrm{L}^{-1}\right)$ & 14 & $8.6(0.9,25.1)$ & 9 & $12.4(2.8,24.5)$ & 0.214 \\
\hline Albumin & 19 & $41.2(37.3,45.0)$ & 20 & $40.6(38.4,47.0)$ & 0.639 \\
\hline Total proteins & 19 & $71.5(64.1,84.6)$ & 20 & $72.6(67.4,78.6)$ & 0.876 \\
\hline
\end{tabular}

BMI, body mass index; CVD, cardiovascular disease; HbA1c, glycated hemoglobin; HDL, high-density lipoprotein; HOMA-IR, homeostasis model of assessment - insulin resistance; HOMA2-B, homeostasis model of assessment beta cell function; IL, interleukin; LDL, low-density lipoprotein; MCP1, monocyte chemotatic protein-1; vAT, visceral adipose tissue; scAT, subcutaneous adipose tissue. 10-Year CVD risk calculated according to D'Agostino et al.27 


\section{POPs in plasma}

The comparison of the measurement of POPs between treated and non-treated women with hypertension is shown in Table 2. Among the selected POPs, in both groups the most frequently detected compound in plasma was $\sum \mathrm{HCH}$ (sum of $\alpha-\mathrm{HCH}, \beta-\mathrm{HCH}$ and $\delta$ $\mathrm{HCH}$ ) present in $86.4 \%$ of the samples in the treated group and $90.5 \%$ in the nontreated group. $p, p^{\prime}$-DDE was not found in the plasma of neither groups. There was no statistically significant difference between the two groups. Concentrations of the sum of all POPs present in plasma did not differ between treated and nontreated women (median $=47.53$ vs median $=37.37 \mathrm{ng} \mathrm{mL}^{-1}, p=0.432$ ).

\section{Table 2. Persistent organic pollutants (POPs) levels in plasma $\left(\mathrm{ng} \mathrm{mL}^{-1}\right)$ and in both visceral (vAT) and subcutaneous (scAT) adipose tissue (ng/g of fat) of the 43 patients.}

\begin{tabular}{|c|c|c|c|c|c|}
\hline & $\%$ & Treated women & $\%$ & Nontreated women & $p$ value \\
\hline \multicolumn{6}{|l|}{ Plasma } \\
\hline $\mathrm{EHCH}$ & 86.4 & $21.64(5.57,49.36)$ & 90.5 & $15.63(2.98,57.83)$ & 0.194 \\
\hline P,P' DDE & - & $<L$ & - & $<L D$ & - \\
\hline EPOPs & 95.5 & $\mid 47.53(8.63,133.80)$ & 95.2 & $37.37(14.20,209.16)$ & 0.432 \\
\hline \multicolumn{6}{|l|}{ vaT } \\
\hline EHCH & 86.4 & $202.77(0.01,485.67)$ & 81.0 & $56.03(0.09,314.29)$ & $0.045^{*}$ \\
\hline P,P'-DOE & 36.4 & $61.00(1.26,201.50)$ & 9.5 & $12.64(2.71,22.58)$ & 0.444 \\
\hline EPOPs & 90.9 & $251.08(23.96,687.18)$ & 90.5 & $66.84(11.25,453.92)$ & $0.016^{*}$ \\
\hline \multicolumn{6}{|l|}{ SCAT } \\
\hline EHCH & 95.5 & $73.86(1.29,323.24)$ & 90.5 & $40.29(1.80,192.63)$ & 0.205 \\
\hline P,P'DDE & 40.9 & $1.48(0.19,2.46)$ & 23.8 & $1.52(0.43,28.70)$ & 1.000 \\
\hline EPOPs & 100.0 & $99.10(16.78,440.35)$ & 95.2 & $70.03(3.74,309.10)$ & 0.757 \\
\hline
\end{tabular}

a percentage of the total number of positive samples. All data are medians (minimum, maximum). $\sum \mathrm{HCH}$, sum of hexachlorocyclohexane; $\mathrm{p}, \mathrm{p}^{\prime}$-DDE, $\mathrm{p}, \mathrm{p}$-dichlorodiphenyldichloroethylene.

Statistical analysis with Mann-Witney: * $p<0.05$.

\section{POPs in vAT and scAT}

Examining the presence of POPs both in vAT and scAT (Table 2), it was possible to assess that, in the treated group, the percentage of samples with detectable concentration of POPs was $90.9 \%$ with median values of 251.08 (ranging from 23.96 to 687.18 ) $\mathrm{ng} \mathrm{g}^{-1}$ of fat in vAT and $100 \%$ with median values of 99.10 (ranging from 16.78 to 440.35) $\mathrm{ng} \mathrm{g}^{-1}$ of fat in scAT. In nontreated women, the percentage of samples with detectable concentration of these compounds was $90.5 \%$ with median values of 68.84 (ranging from 11.25 to 453.92 ) $\mathrm{ng} / \mathrm{g}$ of fat in vAT and $95.2 \%$ with median values of 70.03 (ranging from 3.74 to 309.10$) \mathrm{ng} \mathrm{g}^{-1}$ of fat in scAT. The most frequently detected compound was $\sum \mathrm{HCH}$ present in $86.4 \%$ and $81.0 \%$ for treated and non-treated women, respectively, in vAT. In scAT, $\sum \mathrm{HCH}$ was also the most frequently detectable compound with $95.5 \%$ and $90.5 \%$ detection rates in treated and non-treated women respectively. In treated women, $p, p^{\prime}-$ DDE was detected in $36.4 \%$ of the samples in vAT and $40.9 \%$ of the samples in scAT. In nontreated women, the prior compound was detected in $9.5 \%$ in vAT and $23.8 \%$ in scAT. Concentrations of $\sum \mathrm{HCH}$ (median $=202.77$ vs median $=56.03 \mathrm{ng} \mathrm{g}^{-1}, p=0.045$ ) and concentrations of POPs $($ median $=251.08$ vs median $=68.84, p=0.016)$ in vAT were 
significantly higher in treated women. Concerning scAT, there was no statistically significant difference between the two groups.

\section{Association between POPs and cardiometabolic risk and inflammation in treated women}

The association between POPs levels and the patients' clinical and biochemical parameters is shown in Table 3 . The plasma $\sum \mathrm{HCH}$ concentration was significantly and inversely correlated with $\mathrm{HbA} 1 \mathrm{c}$ and the ratio IL-6/IL-10 and the plasma $\sum$ POPs concentration was inversely correlated with HOMA-IR. Concerning vAT, the presence of $\sum \mathrm{HCH}$ was inversely correlated with plasma albumin and $p, p^{\prime}$-DDE was positively correlated with $\mathrm{HbA1c}$ and plasma IL-10. VAT $\sum$ POPs was positively correlated with 10 -year CVD risk and the count of plasma monocytes. Regarding scAT, the $\sum \mathrm{HCH}$ concentration was positively correlated with scAT adipocyte area and inversely correlated with plasma AST, $p, p^{\prime}$-DDE was positively correlated with plasma MCP-1 and the $\sum$ POPs concentration was positively correlated with scAT adipocyte area and inversely correlated with plasma AST and G-GT.

Table 3. Correlation of clinical and biological characteristics with the sum of hexachlorocyclohexane $\left(\sum \mathrm{HCH}\right), p, p^{\prime}$-dichlorodiphenyldichloroethylene $\left(p, p^{\prime}\right.$-DDE) and persistent organic pollutants (POPs) levels in visceral (vAT) and subcutaneous (scAT) adipose tissue (ng/g of fat) and plasma (ng $\mathrm{mL}^{-1}$ ) of treated women.

\begin{tabular}{|c|c|c|c|c|c|c|c|c|c|c|c|c|c|c|c|c|}
\hline & \multicolumn{16}{|c|}{$\begin{array}{l}\text { Treated } \\
\end{array}$} \\
\hline & $\begin{array}{l}\text { SCAT sdipocyte } \\
\text { srea }\end{array}$ & \begin{tabular}{|l|} 
HDL \\
\end{tabular} & \begin{tabular}{|l|l|} 
LDL \\
\end{tabular} & $\begin{array}{l}\begin{array}{c}\text { Fasting } \\
\text { glycemias }\end{array} \\
\end{array}$ & HbA1C & $\begin{array}{l}\text { HoMA- } \\
\text { IR }\end{array}$ & $\begin{array}{c}\text { Systolic } \\
\text { BP }\end{array}$ & $\begin{array}{c}\text { Diastolic } \\
\mathrm{BP}\end{array}$ & \begin{tabular}{|l|}
$\mathrm{IL}-10$ \\
\end{tabular} & \begin{tabular}{|l||}
$\mathrm{Il}-6 / \mathrm{Il}-10$ \\
\end{tabular} & MCP-1 & Monocytes & 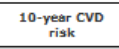 & AST & G-GT & $\begin{array}{l}\text { Albumin } \\
\text { A }\end{array}$ \\
\hline \multicolumn{17}{|c|}{ Plisms } \\
\hline$\overline{E \mathrm{EHCH}}$ & -0.184 & -0.077 & 0.085 & -0.155 & 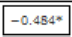 & - & 0.047 & 0.267 & \begin{tabular}{|l|}
0.323 \\
\end{tabular} & $-0.6411 \% x$ & 0.065 & -0.271 & (0.037 & 0.0 .317 & 0.334 & 0.256 \\
\hline 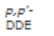 & $\begin{array}{l}- \\
-\end{array}$ & - & - & $\begin{array}{lll}- & -1 \\
\end{array}$ & - & 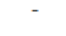 & 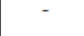 & $\begin{array}{l}- \\
-\end{array}$ & 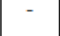 & $\begin{array}{ll}- & - \\
\end{array}$ & 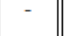 & $\begin{array}{cc}- & - \\
\end{array}$ & $\begin{array}{l}- \\
-\end{array}$ & - & $\begin{array}{lll}- & - \\
\end{array}$ & $\begin{array}{lll}- & - \\
\end{array}$ \\
\hline EPOPs & -0.296 & \begin{tabular}{|l|}
-0.027 \\
\end{tabular} & \begin{tabular}{|l|l|}
-0.108 \\
\end{tabular} & -0.224 & \begin{tabular}{|l|}
-0.131 \\
\end{tabular} & $-0.514^{*}$ & 0.297 & 0.391 & \begin{tabular}{|l|}
0.379 \\
\end{tabular} & -0.191 & 0.215 & -0.275 & 0.047 & $\mid-0.171$ & 0.027 & \begin{tabular}{|l|}
-0.097 \\
\end{tabular} \\
\hline \multicolumn{17}{|c|}{ vaT } \\
\hline$\underline{E H C H}$ & 0.302 & \begin{tabular}{|l|}
-0.025 \\
\end{tabular} & 0.005 & \begin{tabular}{|l|l|l|} 
\\
\end{tabular} & \begin{tabular}{|l|}
-0.045 \\
\end{tabular} & -0.233 & 0.165 & \begin{tabular}{|l|l|}
0.137 \\
\end{tabular} & \begin{tabular}{|l|}
0.082 \\
\end{tabular} & 0.165 & $\mid$ & 0.306 & 0.349 & \begin{tabular}{|l||}
-0.363 \\
\end{tabular} & -0.263 & 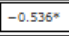 \\
\hline 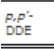 & \begin{tabular}{|l|l|}
-0.071 \\
\end{tabular} & \begin{tabular}{|l|}
0.252 \\
\end{tabular} & 0.238 & 0.337 & $0.771^{*}$ & 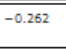 & \begin{tabular}{|l|l|l}
-0.305 \\
\end{tabular} & 0.018 & $0.762^{*}$ & -0.405 & $|-0.429|$ & 0.143 & 0.486 & -0.198 & (0.192 & 0.029 \\
\hline EPOPS & 0.325 & \begin{tabular}{|l|l|}
0.113 \\
\end{tabular} & 0.060 & -0.054 & 0.045 & -0.268 & 0.280 & 0.137 & \begin{tabular}{|l|l|l|l|} 
\\
\end{tabular} & 0.206 & $\mid-0.191$ & $0.492^{*}$ & $0.521^{*}$ & -0.434 & -0.317 & -0.354 \\
\hline \multicolumn{17}{|c|}{$z=\mathrm{AT}$} \\
\hline$\overline{E H C H}$ & $0.569 \mathrm{~m}$ & \begin{tabular}{|l|}
0.217 \\
\end{tabular} & 0.291 & 0.221 & \begin{tabular}{|l|}
-0.056 \\
\end{tabular} & 0.212 & -0.005 & \begin{tabular}{|l|l|l|l}
-0.177 \\
\end{tabular} & \begin{tabular}{|l|}
-0.170 \\
\end{tabular} & 0.135 & $\mid$ & -0.075 & -0.191 & $\left|-0.450^{*}\right|$ & -0.432 & 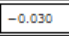 \\
\hline 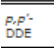 & 0.483 & -0.403 & 0.201 & -0.109 & -0.307 & $\begin{array}{l}-0.400 \\
\end{array}$ & \begin{tabular}{|l|l|l}
0.289 \\
\end{tabular} & $\mid-0.577$ & \begin{tabular}{|l|l|}
-0.071 \\
\end{tabular} & 0.238 & $0.683^{*}$ & \begin{tabular}{|l|l|l|}
-0.017 \\
\end{tabular} & \begin{tabular}{|l|l|l|}
-0.357 \\
\end{tabular} & 0.190 & -0.133 & $\begin{array}{ll}0.033 \\
\end{array}$ \\
\hline EPOPs & $0.0505^{*}$ & \begin{tabular}{|l|l|}
0.255 \\
\end{tabular} & 0.303 & 0.183 & 0.183 & 0.206 & -0.063 & -0.087 & -0.064 & 0.073 & $\mid$ & 0.081 & -0.233 & $\mid-0.455 x$ & $-0.451 *$ & 0.010 \\
\hline
\end{tabular}

AST, aspartate transaminase; BP, blood pressure; CVD, cardiovascular disease; G-GT, gamma-glutamyl transpeptidase; HbA1c, glycated hemoglobin; HDL, high-density lipoprotein; HOMA-IR, homeostasis model of assessment - insulin resistance; IL, interleukin; LDL, low-density lipoprotein; MCP1, monocyte chemotatic protein-1; scAT, subcutaneous adipose tissue. 10-Year CVD risk calculated according to D'Agostino et al.27

Statistical analysis with spearman's correlation: ${ }^{*} \mathrm{p}<0.05$ and ${ }^{* *} \mathrm{p}<0.01$

\section{Association between POPs and cardiometabolic risk and inflammation in nontreated women}

The association between POPs levels and the patients' clinical and biochemical parameters is shown in Table 4 . The plasma $\sum \mathrm{HCH}$ concentration was significantly and inversely correlated with HDL cholesterol and positively correlated with LDL 
cholesterol, plasma IL-10 and 10-year CVD risk. No significant correlation was found between plasma $\sum$ POPs concentration and the different clinical criteria in non-treated women. VAT $\sum \mathrm{HCH}$ concentration was positively correlated with systolic blood pressure. ScAT $\sum \mathrm{HCH}$ and $\sum$ POPs concentrations were positively correlated with systolic blood pressure.

Table 4. Correlation of clinical and biological characteristics with the sum of hexachlorocyclohexane $\left(\sum \mathrm{HCH}\right), p, p^{\prime}$-dichlorodiphenyldichloroethylene $\left(p, p^{\prime}\right.$-DDE) and persistent organic pollutants (POPs) levels in visceral (vAT) and subcutaneous (scAT) adipose tissue (ng/g of fat) and plasma $(\mathrm{ng} / \mathrm{mL})$ of nontreated women.

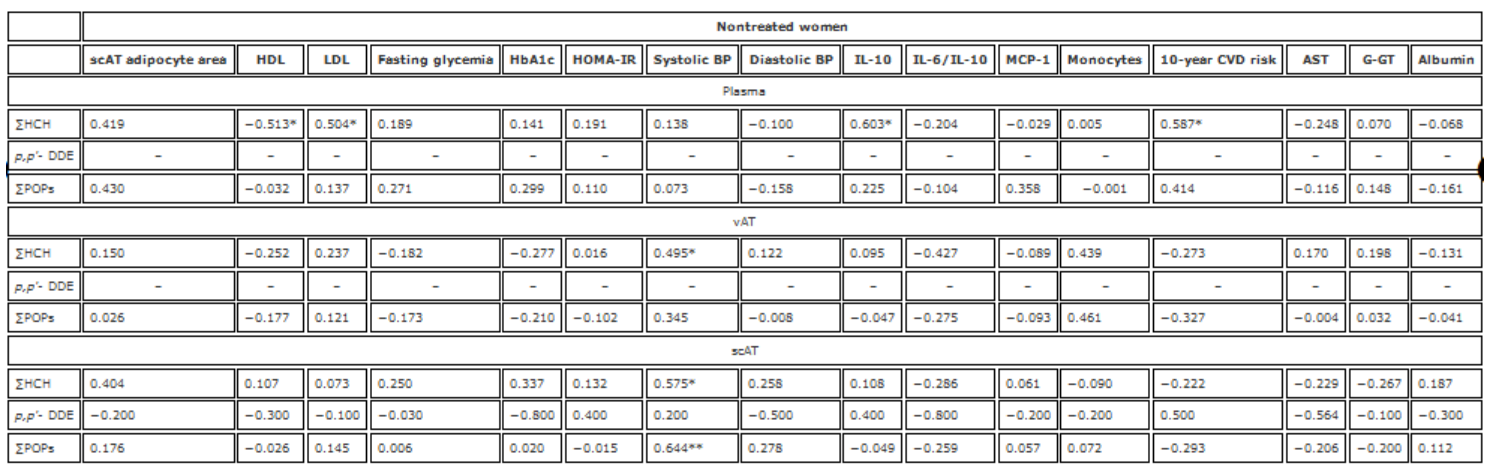

AST, aspartate transaminase; BP, blood pressure; CVD, cardiovascular disease; G-GT, gamma-glutamyl transpeptidase; HbA1c, glycated hemoglobin; HDL, high-density lipoprotein; HOMA-IR, homeostasis model of assessment - insulin resistance; IL, interleukin; LDL, low-density lipoprotein; MCP1, monocyte chemotatic protein-1; scAT, subcutaneous adipose tissue. 10-Year CVD risk calculated according to D'Agostino et al.27

Statistical analysis with spearman's correlation: ${ }^{*} \mathrm{p}<0.05$ and ${ }^{* *} \mathrm{p}<0.01$.

\section{Comparison with women without hypertension}

In addition to the previously described, it was performed a comparison of the clinical and biological parameters between a sample of 19 women with obesity without hypertension and the group of non-treated women, represented by P1, and the group of treated women, represented by $\mathrm{P} 2$. The results are shown in Table 5. In a broader perspective, it was observed a statistically significant difference regarding the duration of obesity between women without hypertension and both groups with hypertension, non-treated women $($ median $=13.0$ vs median $=19.0, p=0.030)$ and treated women (median $=13.0$ vs median $=19.0, p=0.006$ ). As it was expected, blood pressure (BP) is significantly higher in women with hypertension, either with or without treatment for systolic $(p \leq 0.001$, $p=0.024)$ and diastolic BP $(p \leq 0.001, p=0.012)$. Concerning 10-year CVD risk, it was significantly higher in women with hypertension despite the presence of treatment ( $p=0.048, p \leq 0.001)$. Focusing on the comparison between women without hypertension and treated women with hypertension, it was found that treated women were significantly older than women without hypertension (median $=31.0$ vs. median $=40.5, p \leq 0.001$ ). It was also noted that $\mathrm{HbA1c}$ is statistically higher in treated women (median $=5.3 \mathrm{vs}$. median $=5.7, p \leq 0.001$ ). Neither groups revealed no statistical significant difference in other parameters. 


\section{Table 5. Clinical and biological characteristics of the patients.}

\begin{tabular}{|c|c|c|}
\hline Parameters & $P_{1}$ & P2 \\
\hline Age (years) & 1.000 & $<0.001^{*}$ \\
\hline Obestity evolution (yesrs) & $0.030^{*}$ & $0.006^{*}$ \\
\hline \multicolumn{3}{|l|}{ Anthropometric and morphometric measurements } \\
\hline BMI $\left(\mathrm{kg} \mathrm{m}^{-2}\right)$ & 1.000 & 1.000 \\
\hline Waist/hip ratio & 1.000 & 1.000 \\
\hline vaT adiposteste ares $\left(\mu m^{2}\right)$ & 1.000 & 1.000 \\
\hline scaT a aliporyte ares $\left(\mu \mathrm{m}^{2}\right)$ & 1.000 & 0.090 \\
\hline \multicolumn{3}{|l|}{ Plasma lipid profile } \\
\hline Total cholesterol $\left(\mathrm{mg} \mathrm{OL}^{-3}\right)$ & 0.645 & 1.000 \\
\hline Total triglycerides $\left(m g \mathrm{dL}^{-2}\right)$ & 0.615 & 1.000 \\
\hline HDL enolesterol ( $\mathrm{mg} \mathrm{aL}^{-3}$ ) & 1.000 & 0.960 \\
\hline LDL eholesterol $\left(\mathrm{mg} \mathrm{oL}^{-2}\right)$ & 0.615 & 1.000 \\
\hline \multicolumn{3}{|l|}{ Glucose homeostasis } \\
\hline Fasting glycemis (mg ol-12) & 0.576 & 0.687 \\
\hline HDale (\%) & 0.939 & $<0.001^{*}$ \\
\hline HOMA-IR & 1.000 & 0.603 \\
\hline HOMA2-B (\$6) & 0.213 & 0.090 \\
\hline \multicolumn{3}{|l|}{ Blood pressure } \\
\hline Systolic blood pressure (mm $\mathrm{Hg}$ ) & $<0.001^{*}$ & $0.024^{*}$ \\
\hline Disstolis blood pressure $(\mathrm{mm} \mathrm{Hg})$ & $<0.001^{*}$ & $0.012^{*}$ \\
\hline \multicolumn{3}{|l|}{ Inflammatory parameters } \\
\hline $\mathrm{IL}\left(\mathrm{pg} \mathrm{mL}^{-3}\right)$ & 1.000 & 1.000 \\
\hline FL10 $\left(\mathrm{pg} \mathrm{mL^{-3 } )}\right.$ & 0.939 & 1.000 \\
\hline IL6/LL10 & 1.000 & 0.876 \\
\hline$M C P 1\left(p g \mathrm{~mL}^{-3}\right)$ & 1.000 & 1.000 \\
\hline \multicolumn{3}{|l|}{ Other parrameters } \\
\hline hac - resctive protein $\left(m g L^{-1}\right)$ & 0.594 & 1.000 \\
\hline Estradial $\left(\mathrm{pg} \mathrm{mL}^{-1}\right)$ & 1.000 & 0.204 \\
\hline Monocytes (\$) & 1.000 & 1.000 \\
\hline 10-Year CVD risk (\%) & $0.045^{*}$ & $<0.001^{*}$ \\
\hline \multicolumn{3}{|l|}{ Hepatic function } \\
\hline Aspartate transaminase $\left(U \mathrm{LL}^{-1}\right)$ & 1.000 & 1.000 \\
\hline Alsnina transamingse $\left(U L^{-1}\right)$ & 1.000 & 0.828 \\
\hline Gamma-glutamyl transpeptidase (U L Lا-13) & 1.000 & 1.000 \\
\hline Albumin & 1.000 & 1.000 \\
\hline Total proteins & 1.000 & 1.000 \\
\hline
\end{tabular}

P1: nonhypertensive women vs. nontreated hypertensive women; P2: nonhypertensive women vs. treated hypertensive women.

BMI, body mass index; CVD, cardiovascular disease; HbA1c, glycated hemoglobin; HDL, high-density lipoprotein; HOMA-IR, homeostasis model of assessment - insulin resistance; HOMA2-B, homeostasis model of assessment beta cell function; IL, interleukin; LDL, low-density lipoprotein; MCP1, monocyte chemotatic protein-1; vAT, visceral adipose tissue; scAT, subcutaneous adipose tissue. 10-Year CVD risk calculated according to D'Agostino et al. ${ }^{27}$.

Statistical analysis with Mann-Whitney test with bonferroni correction for multiple comparisons: $* p<0.05$.

The comparison of the measurement of POPs between women without hypertension and treated women is shown in Table 6. The comparison with the group of nontreated women revealed no statistically significant results. Among the selected POPs, in both groups the most frequently detected compound in plasma was $\sum \mathrm{HCH}$ present in $86.4 \%$ of the samples in the treated group and 52.6\% in the group without hypertension. $p, p$-DDE was not found in the plasma of neither groups. It was found that the plasmatic levels of $\sum \mathrm{HCH}$ and $\sum$ POPs were significantly higher in the group of treated women with hypertension comparing to women without hypertension $-($ median $=8.72 \mathrm{vs}$. median $=21.64 \mathrm{ng} \mathrm{mL} \leq$, $p=0.018)$, $($ median $=32.61$ vs. median $=47.53 \mathrm{ng} \mathrm{mL} \leq, p=0.015)$, respectively. Despite it was feasible to measure the concentration of POPs in AT in both groups, there was no statistically significant differences between them. Also comparing the group without 
hypertension with the non-treated group with hypertension, there were no differences to report.

Table 6. Persistent organic pollutants (POPs) levels in plasma $(\mathrm{ng} / \mathrm{mL})$ and in both visceral (vAT) and subcutaneous (scAT) adipose tissue (ng/g of fat) of the 43 patients.

\begin{tabular}{|c|c|c|c|c|c|}
\hline & 960 & Women without hypertension & $\%=$ & Treated women with hypertension & $p$ value \\
\hline \multicolumn{6}{|l|}{ Plasma } \\
\hline EHCH & 52.6 & $8.72(4.81,23.47)$ & 86.4 & $21.64(5.57,49.36)$ & $0.018^{*}$ \\
\hline$P, P^{\prime}=\mathrm{DDE}$ & - & $<10$ & - & $<L$ & - \\
\hline EPOPS & 89.5 & $32.61(2.17,54.87)$ & 95.5 & $47.53(8.63,133.80)$ & $0.015^{*}$ \\
\hline \multicolumn{6}{|l|}{ vAT } \\
\hline EHCH & 86.4 & $202.77(0.01,455.67)$ & 86.4 & $202.77(0.01,485.67)$ & 0.111 \\
\hline$P, P^{\prime}-D D E$ & 21.1 & $25.53(12.25,257.52)$ & 36.4 & $61.00(1.26,201.50)$ & 1.000 \\
\hline EPOPs & 100.0 & $106.03(0.28,499.76)$ & $\mid 90.9$ & $251.08(23.96,687.18)$ & 0.192 \\
\hline \multicolumn{6}{|l|}{ SCAT } \\
\hline $\mathrm{EHCH}$ & 95.5 & $73.86(1.29,323.24)$ & 95.5 & $73.86(1.29,323.24)$ & 0.120 \\
\hline$P, P^{\prime}-D D E$ & 31.6 & $3.56(1.19,30.14)$ & 40.9 & $1.45(.19,2.46)$ & 0.177 \\
\hline EPOPS & 100.0 & $56.49(1.44,360.45)$ & 100.0 & $99.10(16.78,440.35)$ & 0.573 \\
\hline
\end{tabular}

a- percentage of the total number of positive samples. All data are medians (minimum, maximum). $\sum \mathrm{HCH}$, sum of hexachlorocyclohexane; p,p'-DDE, p,p'-dichlorodiphenyldichloroethylene.

Statistical analysis with Mann-Witney with bonferroni correction for multiple comparisons: *p $<0.05$.

\section{Discussion}

In the present study, we present a comparison between the cardiometabolic and inflammatory profile of women with obesity and hypertension with or without antihypertensive treatment. The absence of treatment may have many explanations. This cohort could only have obesity as cardiovascular risk factor and mild hypertension or high normal blood pressure (BP) or white-coat hypertension and, as a first step, the physician could attempt life style changes, for a suitable period of time. $\frac{10}{}$ This specific population was already at risk of developing metabolic syndrome, since they had class II or III obesity undergoing bariatric surgery. This metabolic surgery promotes weight loss and improvement or resolution of comorbid risk factors and cardiovascular risk. $. \underline{30}, \underline{31}$

Because of the recent studies relating the exposure to certain environmental factors (POPs) to metabolic syndrome and increase in cardiometabolic risk,,$\underline{5,16}$ we thought it would be interesting to evaluate the distribution of several POPs in human AT and plasma of these two clusters, and its association with cardiometabolic and inflammatory profile in premenopausal women with obesity and hypertension.

Every day, humans are exposed to mixtures of POPs, making it difficult to establish an association between body concentration of a single POP and certain comorbidity, possibly attributable to the different interactions among several of these compounds, and not taking the "cocktail effect" into consideration. $\frac{32}{}$ As endocrine disruptors chemicals (EDCs), defined by the World Health Organization (WHO) as "an exogenous substance or mixture that alters the function(s) of the endocrine system and consequently causes adverse health effects in an intact organism, or its progeny or (sub) populations," 3 -35 they comprise a vast number of compounds with distinct chemical structures and properties. $. \underline{36}, \underline{37}$ Indeed, adding a layer of complexity to their effects, these chemicals can act through a multiplicity of mechanisms, namely through nuclear receptors, nonnuclear 
steroid hormone receptors, $\stackrel{38}{-}$ nonsteroid receptors (eg, neurotransmitter receptors), orphan receptors [such as aryl hydrocarbon receptor (AhR)] and also in pathways related to steroid biosynthesis and/or metabolism or on other actions that may impose onto the endocrine system, such as oxidative stress, mitochondrial dysfunction and epigenetic modifications. $\underline{39}$

We could assess that virtually all subjects present in this study had detectable quantities of POPs in the different depots. Also, the concentration of the compounds analyzed in the present study ( $\sum \mathrm{HCH}$ and $\sum$ POPs) in vAT was significantly higher in treated women, but $p, p^{\prime}$-DDE levels were similar in both groups. On the other hand, both POPs concentrations in scAT and plasma were similar between the two groups. Although the depot differences regarding POP levels is not consistent within the literature,,$\underline{5,16} \underline{40-43}$ the heterogeneous distribution verified in this study has also been reported in other studies, suggesting that, even though scAT is an accessible compartment for measurement of contamination levels, it is not representative of POPs levels in vAT, a highly metabolically active tissue associated with metabolic dysregulation. $, \underline{5}, \underline{40}, \underline{41}$ In fact, only in nontreated women the levels of POPs in both AT depots were positively correlated $\left(R_{\mathrm{S}}=0.534, p<0.05\right)$. POPs' plasmatic levels were also not representative of the other compartments, as POPs levels in VAT and scAT were not correlated with plasma POPs in none of the groups (data not shown) and some compounds, such as $p, p^{\prime}$-DDE, were not detected in these women. This could be related to the physicochemical properties of each compound and metabolic rates of the subjects in this study.

Comparing different clinical and metabolic parameters, we observed a significant increase in the adipocytes' area from scAT in the group without treatment. Because obesity is characterized by adipocyte hypertrophy and hyperplasia, $, 2,44$ this population has an overall increase in adipocyte area when compared to lean individuals. However, this statistical difference in the, assumingly, "healthier" group, is accordant with a protective storage of POPs in this particular type of AT. The lower metabolic activity, lipolysis rate and capillary filtration coefficient of scAT comparing to vAT leads to a lower release of these pollutants to the bloodstream 12,41 and we conjecture that this distribution pattern has less repercussions in metabolic function. Because it has an increased area, the distribution of POPs in scAT may be more diluted in nontreated women, explaining how we obtained lower detection rates in this group.

Then, we addressed the effects of POPs on metabolism by exploring correlations between their concentration and clinical and metabolic parameters.

Visceral obesity is correlated to the development of several comorbidities such as T2DM, dyslipidemia, insulin resistance and cardiovascular disease. $\frac{45}{}$ This appears to originate from disturbance in AT function leading to a chronic inflammatory state and to dysregulation of the endocrine and paracrine actions of adipocyte-derived factors. $\frac{46}{}$ Obesity leads to an up-regulation of pro-inflammatory adipokines (eg IL-6 and MCP-1) and decrease of anti-inflammatory (IL-10) factors. ${ }^{47}$ IL- 6 contributes to the development of insulin resistance, while MCP-1 promotes macrophage accumulation in AT. .49

Indeed, our cluster under medical therapy had a significantly higher amount of POPs in vAT and we observed that their presence was associated with a higher 10-year CVD risk and an increased inflammatory response in favor of an increased account of circulating monocytes, possibly migrating to the AT. The concentration of $p, p^{\prime}$-DDE was correlated 
with an increase of $\mathrm{HbA1c}$, probably to an increase of insulin resistance, and an increase of IL-10.

On the other hand, we observed a positive correlation between the presence of vAT $\sum \mathrm{HCH}$ and systolic blood pressure in the non-treated group. This was also verified with the presence of $\sum \mathrm{HCH}$ and $\sum$ POPs in scAT. These associations are suggestive of a contribution of these compounds to the development of arterial hypertension, and even, its severity.

In this study, we found interesting results showing clinical correlations with plasmatic levels of $\sum \mathrm{HCH}$ and of $\sum$ POPs. In the treated group, we found a decreased insulin resistance, translated by a decrease of HbA1c and HOMA-IR. This could be partially explained by the preferential use of antihypertensive drugs, such as angiotensin receptor blockers (ARBs) or calcium channel blockers, which potentially improve insulin sensitivity in this specific population in risk of development, or already with, metabolic syndrome. $\stackrel{10}{ }$ Attending that most POPs have endocrine disruption effects, some of which display estrogenic activity, they were designed as xenoestrogens (XE). $\underline{50}$ Several researches report that overstimulation of estrogen receptors present in pancreatic $\beta$-cells, by these particular compounds, may produce an excessive insulin signaling, culminating in insulin resistance. $\frac{51}{}$ This suggests that XE may increase insulin resistance and risk of developing T2DM primarily by modulating $\beta$-cell function. .51 Perlstein et al. showed that ARB therapy improved pancreatic $\beta$-cell function in stage I hypertensive obese patients with insulin resistance, even though there were no changes in insulin sensitivity. $\underline{52}$ However, the role of the interaction of these drugs and circulating POPs is yet to be explained. Also, it was possible to verify a decrease of IL-6/IL-10 ratio which indicates a shift towards an anti-inflammatory response.

In respect to nontreated women, it was observed several correlations with the plasma levels of $\sum \mathrm{HCH}$. First of all, there was a dislipidemic pattern due to a decrease of HDLcholesterol and an increase of LDL-cholesterol. Dyslipidemia is a major risk factor for

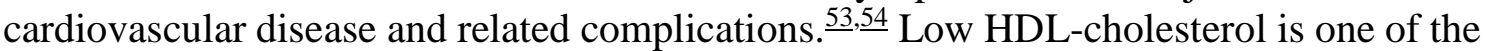
criteria diagnostic of metabolic syndrome, often with normal LDL-cholesterol. $\underline{13}$ Accordingly, there seems to exist an influence of POPs in lipid metabolism, however since different POPs may be related to different metabolic traits, it is difficult to study this association. Besides, as dyslipidemia is an early manifestation of insulin resistance related conditions and it is often detectable before the development of clinical diagnostic criteria of T2DM, lipid concentrations may be intermediaries in the associations between POPs and type 2 diabetes. $\frac{55}{}$ In addition, it was observed a positive correlation with 10year CVD risk, in a population already at risk because of severe obesity and hypertension.

Because our objective was to evaluate the effects of POPs in a sample of women with hypertension, it seemed of interest to assess the concentration of POPs in a similar sample without hypertension and compare the same parameters evaluated with the treated and non-treated groups with hypertension.

Several studies evaluated the association between the obesity duration and incident hypertension, however although duration of obesity was associated with an increased risk of incident hypertension, it is thought that this interaction is attenuated once adjusted for BMI..$\underline{56}$ Indeed, the sample of women without hypertension revealed less years of obesity 
duration comparing to both groups with hypertension, however there was no significant differences when comparing BMI.

Also, when comparing the group without hypertension with both groups with hypertension, as it was expected, the latter had significantly higher 10-year CVD risk, despite the presence of treatment. Both hypertension and obesity have been identified as independent risk factors for cardiovascular disease $\frac{57-59}{2}$ although it appears that the CVD risk is significantly higher in overweight/obese patients..$\underline{58}$

It was obtained interesting results, revealing a higher plasmatic circulating concentration of $\sum \mathrm{HCH}$ and of $\sum$ POPs in the group under medical antihypertensive therapy comparing to the group without hypertension. This is in favor of a harmful process ongoing after the release of POPs from AT to circulation and perpetuation of its toxic effects in multiple areas. It was also noted that $\mathrm{HbA} 1 \mathrm{c}$ is statistically higher in treated women, revealing a worst metabolic profile in this group. This could be associated with metabolic syndrome and even the circulating POPs. It has been associated that elevated circulating levels of POPs could be related to hypertension, obesity, diabetes, metabolic syndrome, and cardiovascular disease in humans. $\underline{60-62}$

The limitations of this study rest in our small, very specific population, whether hypertension control has been optimized, if there is compliance and unawareness of the course duration of antihypertensive treatment. As well, the patients were at the "end-ofline" of obesity treatment which limits the generalization of our findings to the overall population. Also, since the data was retrieved from electronic medical records, there is no additional information concerning the diagnostic cutoff used, the exact duration of hypertension and its multiorganic impact.

Nonetheless, our study has significant assets regarding the characterization of environmental exposures in three tissue compartments (plasma, visceral fat and subcutaneous fat) in treated and nontreated women with obesity and hypertension undergoing bariatric surgery and analysis of the results according to hypertensive status, exploring a differential link to the metabolic abnormalities and cardiovascular risk.

\section{Conclusion}

Our findings suggest that the exposure of POPs and its accumulation in vAT and circulating in plasma may be related to a higher cardiovascular risk in women with obesity and hypertension, with or without antihypertensive treatment, respectively. It was also verified that in a similar cohort without hypertension, the circulating concentrations of POPs were significantly lower than medical treated women with hypertension. Assuming that circulating POPs derive from release of vAT, $\underline{16}$ detecting concentrations in vAT may be useful to determine an earlier use of antihypertensive treatment to attenuate an ongoing deleterious process, either related to insulin resistance and T2DM, as cardiovascular events such as stroke, coronary events and heart and renal failure.

\section{Human ethics committee}


The participation of the human subjects did not occur until after informed consent was signed. The study protocol was approved by the S. João Hospital's Ethics Committee (Porto, Portugal).

$\begin{array}{ll}\text { Abbreviations } \\ \text { AT } & \text { adipose tissue } \\ \text { BMI } & \text { body mass index } \\ \text { BP } & \text { blood pressure } \\ \text { CVD } & \text { cardiovascular disease } \\ \text { POPs } & \text { persistent organic pollutants } \\ \text { p,p'-DDE } & \text { p,p'-dichlorodiphenyldichloroethylene } \\ \text { scAT; } \Sigma \text { HCH subcutaneous adipose tissue } \\ \text { T2DM } & \text { sum of hexachlorocyclohexane; type 2 diabetes mellitus } \\ \text { vAT } & \text { visceral adipose tissue } \\ \text { XE } & \text { xenoestrogens }\end{array}$

\section{References}

- Ng M, Fleming T, Robinson M, et al. Global, regional, and national prevalence of overweight and obesity in children and adults during 1980-2013: a systematic analysis for the global burden of disease study 2013. Lancet. 2014;384(9945):766-781.

- Bastien M, Poirier P, Lemieux I, et al. Overview of epidemiology and contribution of obesity to cardiovascular disease. Prog Cardiovasc Dis. 2014;56(4):369-381.

- Collaboration NCDRF. Worldwide trends in body-mass index, underweight, overweight, and obesity from 1975 to 2016: a pooled analysis of 2416 populationbased measurement studies in 128.9 million children, adolescents, and adults. Lancet. 2017;390(10113):2627-2642

- Baillie-Hamilton PF. Chemical toxins: a hypothesis to explain the global obesity epidemic. J Altern Complem Med. 2002;8(2):185-192.

- Pestana D, Faria G, Sá C, et al. Persistent organic pollutant levels in human visceral and subcutaneous adipose tissue in obese individuals - depot differences and dysmetabolism implications. Environ Res. 2014;133(0):170-177

- Grün F, Blumberg B. Endocrine disrupters as obesogens. Mol Cell Endocrinol. 2009;304(1/2):19-29.

- Schafer KS, Kegley SE. Persistent toxic chemicals in the US food supply. J Epidemiol Commun Health. 2002;56(11):813-817.

- Casals-Casas C, Desvergne B. Endocrine disruptors: from endocrine to metabolic disruption. Annu Rev Physiol. 2011;73:135-162.

- Huang X, Lessner L, Carpenter DO. Exposure to persistent organic pollutants and hypertensive disease. Environ Res. 2006;102(1):101-106

- Mancia G, Fagard R, Narkiewicz K, et al. 2013 ESH/ESC practice guidelines for the management of arterial hypertension. Blood Press. 2014;23(1):3-16

- Arrebola JP, Fernández MF, Martin-Olmedo P, et al. Historical exposure to persistent organic pollutants and risk of incident hypertension. Environ Res. 2015;138:217-223. 
- La Merrill M, Emond C, Kim MJ, et al. Toxicological function of adipose tissue: focus on persistent organic pollutants. Environ Health Perspect. 2013;121(2):162-169.

- Lee D-H, Steffes MW, Sjödin A, et al. Low dose organochlorine pesticides and polychlorinated biphenyls predict obesity, dyslipidemia, and insulin resistance among people free of diabetes. PLoS One. 2011;6(1):e15977.

- Lind PM, van Bavel B, Salihovic S, et al. Circulating levels of persistent organic pollutants (POPs) and carotid atherosclerosis in the elderly. Environ Health Perspect. 2012;120(1):38-43.

- Mastin JP. Environmental cardiovascular disease. Cardiovasc Toxicol. 2005;5(2):91-94.

- Teixeira D, Pestana D, Santos C, et al. Inflammatory and cardiometabolic risk on obesity: role of environmental xenoestrogens. J Clin Endocrinol Metab. 2015;100(5):1792-801.

- Fry K, Power MC. Persistent organic pollutants and mortality in the United States, NHANES 1999-2011. Environ Health. 2017;16(1):105.

- Lim J-E, Lee S, Lee S, et al. Serum persistent organic pollutants levels and stroke risk. Environ Pollut. 2018;233:855-861.

- Pestana D, Teixeira D, Meireles M, et al. Adipose tissue dysfunction as a central mechanism leading to dysmetabolic obesity triggered by chronic exposure to p,p'DDE. Sci Rep. 2017;7(1):2738.

- Donat-Vargas C, Åkesson A, Tornevi A, et al. Persistent organochlorine pollutants in plasma, blood pressure, and hypertension in a longitudinal study. Hypertension. 2018;71(6):1258-1268.

- Park SH, Lim J-E, Park H, et al. Body burden of persistent organic pollutants on hypertension: a meta-analysis. Environ Sci Pollut Res Int. 2016;23(14):1428414293.

- rsenescu V, Arsenescu R, Parulkar M, et al. Polychlorinated biphenyl 77 augments angiotensin II-induced atherosclerosis and abdominal aortic aneurysms in male apolipoprotein $\mathrm{E}$ deficient mice. Toxicol Appl Pharmacol. 2011;257(1):148-154

- Kopf PG, Huwe JK, Walker MK. Hypertension, cardiac hypertrophy, and impaired vascular relaxation induced by 2,3,7,8-tetrachlorodibenzo-p-dioxin are associated with increased superoxide. Cardiovasc Toxicol. 2008;8(4):181-193.

- Lind PM, Orberg J, Edlund U-B, et al. The dioxin-like pollutant PCB 126 (3,3',4,4',5-pentachlorobiphenyl) affects risk factors for cardiovascular disease in female rats. Toxicol Lett. 2004;150(3):293-299.

- Wallace TM, Levy JC, Matthews DR. Use and abuse of HOMA modeling. Diabetes Care. 2004;27(6):1487-1495

- Friedewald WT, Levy RI, Fredrickson DS. Estimation of the concentration of low-density lipoprotein cholesterol in plasma, without use of the preparative ultracentrifuge. Clin Chem. 1972;18(6):499-502.

- D'Agostino RB, Vasan RS, Pencina MJ, Sr., et al. General cardiovascular risk profile for use in primary care: the Framingham Heart Study. Circulation. 2008;117(6):743-753.

- Covaci A. Application of solid-phase disk extraction combined with gas chromatographic techniques for determination of organochlorine pesticides in human body fluids. In: Martínez Vidal J, Frenich A, eds. Pesticide Protocols. Humana Press; 2006:49-59. 
- Fernandes VC, Pestana D, Monteiro R, et al. Optimization and validation of organochlorine compounds in adipose tissue by SPE-gas chromatography. Biomed Chromatogr. 2012;26(12):1494-1501

- Maggard-Gibbons M, Maglione M, Livhits M, et al. Bariatric surgery for weight loss and glycemic control in nonmorbidly obese adults with diabetes: a systematic review. JAMA 2013;309(21):2250-2261.

- Beamish AJ, Olbers T, Kelly AS, et al. Cardiovascular effects of bariatric surgery. Nat Rev Cardiol. 2016;13(12):730-743.

- Arrebola JP, Pumarega J, Gasull M, et al. Adipose tissue concentrations of persistent organic pollutants and prevalence of type 2 diabetes in adults from Southern Spain. Environ Res. 2013;122:31-37.

- Bergman A, Andersson A, Becher G, et al. Science and policy on endocrine disrupters must not be mixed: a reply to a "common sense" intervention by toxicology journal editors. Environ Health 2013;12:69.

- IPCS, Global Assessment of the State-of-the-Science of Endocrine Disruptors. International Programme on Chemical Safety. Geneva: World Health Organization and United Nations Environment Programme. 2002.

- WHO/UNEP. State of the science of Endocrine Disrupting Chemicals 2012. Geneva: United Nations Environment Programme and World Health Organization; 2013

- Trasande L, Zoeller RT, Hass U, et al. Estimating burden and disease costs of exposure to endocrine-disrupting chemicals in the European union. J Clin Endocrinol Metab. 2015;100(4):1245-1255.

- Li Y, Luh CJ, Burns KA, et al. Endocrine-disrupting chemicals (EDCs): In vitro mechanism of estrogenic activation and differential effects on ER target genes. Environ Health Perspect. 2013;121(4):459-466.

- Prossnitz ER, Barton M. Estrogen biology: new insights into GPER function and clinical opportunities. Mol Cell Endocrinol. 2014;389(1/2):71-83

- Sanderson JT. The steroid hormone biosynthesis pathway as a target for endocrine-disrupting chemicals. Toxicol Sci. 2006;94(1):3-21.

- u GW, Laseter J, Mylander C. Persistent organic pollutants in serum and several different fat compartments in humans. J Environ Public Health. 2011;2011:1.

- Kim K-S, Lee Y-M, Kim SG, et al. Associations of organochlorine pesticides and polychlorinated biphenyls in visceral vs. subcutaneous adipose tissue with type 2 diabetes and insulin resistance. Chemosphere. 2014;94:151-157.

- Kim M-J, Marchand P, Henegar C, et al. Fate and complex pathogenic effects of dioxins and polychlorinated biphenyls in obese subjects before and after drastic weight loss. Environ Health Perspect. 2011;119(3):377-383.

- Dewailly E, Mulvad G, Pedersen HS, et al. Concentration of organochlorines in human brain, liver, and adipose tissue autopsy samples from Greenland. Environ Health Perspect. 1999;107(10):823-828.

- Lafontan M. Adipose tissue and adipocyte dysregulation. Diabetes Metab. 2014;40(1):16-28.

- Roriz AKC, Passos LCS, de Oliveira CC, et al. Evaluation of the accuracy of anthropometric clinical indicators of visceral fat in adults and elderly. PLoS One. 2014;9(7):e103499.

- Iantorno M, Campia U, Di Daniele N, et al. Obesity, inflammation and endothelial dysfunction. J Biol Regul Homeost Agents. 2014;28(2):169-176. 
- McLaughlin T, Liu L-F, Lamendola C, et al. T-cell profile in adipose tissue is associated with insulin resistance and systemic inflammation in humans. Arterioscler Thromb Vasc Biol. 2014;34(12):2637-2643.

- Myre M, Imbeault P. Persistent organic pollutants meet adipose tissue hypoxia: does cross-talk contribute to inflammation during obesity?. Obes Rev. 2014;15(1):19-28.

- uster JJ, Ouchi N, Gokce N, et al. Obesity-induced changes in adipose tissue microenvironment and their impact on cardiovascular disease. Circ Res. 2016;118(11):1786-1807.

- Ociepa-Zawal M, Rubis B, Wawrzynczak D, et al. Accumulation of environmental estrogens in adipose tissue of breast cancer patients. J Environ Sci Health A Tox Hazard Subst Environ Eng. 2010;45(3):305-312.

- Nadal A, Alonso-Magdalena P, Soriano S, et al. The pancreatic beta-cell as a target of estrogens and xenoestrogens: implications for blood glucose homeostasis and diabetes. Mol Cell Endocrinol. 2009;304(1/2):63-68.

- Perlstein TS, Henry RR, Mather KJ, et al. Effect of angiotensin receptor blockade on insulin sensitivity and endothelial function in abdominally obese hypertensive patients with impaired fasting glucose. Clin Sci. 2012;122(4):193-202.

- Pandeya A, Sharma M, Regmi P, et al. Pattern of dyslipidemia and evaluation of non-HDL cholesterol as a marker of risk factor for cardiovascular disease in type 2 diabetes mellitus. Nepal Med Coll J. 2012;14(4):278-282

- Corey KE, Chalasani N. Management of dyslipidemia as a cardiovascular risk factor in individuals with nonalcoholic fatty liver disease. Clin Gastroenterol Hepatol. 2014;12(7):1077-1084. quiz e59-60.

- Lee D-H, Steffes MW, Sjödin A, et al. Low dose of some persistent organic pollutants predicts type 2 diabetes: a nested case-control study. Environ Health Perspect. 2010;118(9):1235-1242.

- Tanamas SK, Wong E, Backholer K, et al. Duration of obesity and incident hypertension in adults from the Framingham Heart Study. J Hypertens. 2015;33(3):542-545.

- Kannel WB. Risk stratification in hypertension: new insights from the Framingham Study. Am J Hypertens. 2000;13(1, Part 2):3S-10S.

- Neves AL, Couto L. Cardiovascular risk in overweight/obese and lean hypertensive patients. Rev Port Cardiol. 2014;33(4):223-228.

- Kannel WB. Hypertension: reflections on risks and prognostication. Med Clin North Am. 2009;93(3):541

- Barrett JR. Atherosclerosis predictor? Circulating levels of POPs linked to arterial effects. Environ Health Perspect. 2012;120(1):A34.

- Lind L, Lind PM. Can persistent organic pollutants and plastic-associated chemicals cause cardiovascular disease?. J Intern Med. 2012;271(6):537-553.

- Park W-H, Jun DW, Kim JT, et al. Novel cell-based assay reveals associations of circulating serum AhR-ligands with metabolic syndrome and mitochondrial dysfunction. Biofactors. 2013;39(4):494-504.

\section{- Additional information}

\section{Funding}

This work was supported by FCT (Fundo Social Europeu, Programa Operacional Potencial Humano da EU (POPH); PEst-OE/SAU/UI0038/2011; SFRH/BD/46640/2008, 
SFRH/BD/64691/2009), and Projetos de Investigação na Pré-graduação 2011, Universidade do Porto. 